\title{
AI NEED IN DIGITAL TRANSFORMATION IN INDIAN MANUFACTURING MANAGEMENT MAKING IT INTELLIGENT SMART FACTORY
}

\author{
MILAN KUMAR, REVATHI VENKATARAMAN \& N. PARTHIBHAN
}

SRM Institute of Science and Technology, Kattankulathur, Tamilnadu, India

\begin{abstract}
Growing technologies, with rising demand for process output in Indian factories drive automation processes that make high profits for the industry. This AI led digital transformation enables equipment selfconfiguration, predictive cap abilities, integration of connected devices with results from AI technology, manufacturing intelligence called "Smart Factory."

Keywords: Digital Transformation, Smart Devices, Sensors
\end{abstract}

Received: Jun 08, 2020; Accepted: Jun 28, 2020; Published: Sep 19, 2020; Paper Id.: IJMPERDJUN20201344

\section{INTRODUCTION}

Indian industry has changed rapidly due to digital automation, it is important to design Smart factory item, decentralizing, visualizing, real-time capacity, integration in vertical and horizontal areas, stock adaptation, company social significance, and manufacturing path $\left[{ }^{1},{ }^{2}\right]$. In Figure.1.explains the digital innovation that brings "Intelligence" with smart devices, sensors, data and analytics to manufacturing $\left[{ }^{3}\right]$.

\begin{tabular}{|l|l|l|l|}
\hline Industry 1.0 & 1784 & First Industrial Revolution & Steam engine (first machinery) \\
\hline Industry 2.0 & 1870 & Second Industrial Revolution & Electric Power (first production line) \\
\hline Industry 3.0 & 1969 & Third Industrial Revolution & Logic controller \\
\hline Industry 4.0 & 2013 & Fourth Industrial Revolution & German introduced industry 4.0 \\
\hline
\end{tabular}

Figure 1: Industrial Growth.

Industry $\quad 4.0 \quad(\mathrm{I}-\quad 4.0) \quad$ concepts $\quad$ are: $\quad$ Smart
digitalorscalabledevelopment,compatibility,design,decentralizing, virtualising, flexibility in real time, vertical and horizontal integration, stock differentiation, business social interest and company orientation $\left[{ }^{4}\right]$.The advanced fast, adaptive, human-machine communication and scalable technologies $\left[5,{ }^{5}, 3\right]$ neededI-4.0definitionbringing $\left[{ }^{6}\right]$ Small and Mid-sized enterprises (SMEs) towards the digital world by means of innovations Like Cyber- Physical Services (CPS), Big Data Analysis, Internet of Peoples (IoP), Cognitive and Cloud services, Additive Manufacturing, Blockchain, Cryptography, Increased Reality, Simulation, Enterprise Architecture and Integration (EA EI), Modeling, Semantic Automation and Business Robotics $\left[{ }^{7},{ }^{2}\right]$. The Internet of Services and Information and Communications Technology (ICT) $\left.{ }^{2}\right]$ are connected to the Internet of Things (IoT) which results Intelligent manufacturing called "smart factory". I- 4.0 technology is self-optimisation, self-adaptation with centralized networks that digitize market development $\left[{ }^{8}\right]$. This is used to provide a better way to tackle complex $\left[{ }^{9}\right]$ issues with efficiency and income improvements $\left[{ }^{10}\right]$. The Key measurement is developing, updating, analyzing, monitoring 
and continuous improvement of automated manufacturing systems, also known as the 'Intelligent or Smart Factory' [ $\left.{ }^{11}\right]$. It focuses primarily on integration process within and around enterprise boundaries, mainly on predictive maintenance and real time access to mobile. information $\left[{ }^{12}\right]$.

\section{DIGITAL TECHNOLOGY SMARTFACTORY NEEDS}

The digital technologies linked IoT, which interacted with each other machines and automatically took better decisions $\left[{ }^{13}\right]$. Value and strategy focused on IoT domains, stakeholders and business models[ $\left.{ }^{14}\right]$.

\section{i) IoT}

IoT in I-4.0 also known as Industrial IoT (IIoT), which addresses the networks in industry $\left[{ }^{15}\right]$. It involves the digital transformation of machinery's products/ goods, processes, and production including computer activity simulations (3D). This provides greater visibility and customer insights into manufacturing operations. System controls, middleware and medical devices are integrated, storage facilities for backend cloud services. $\left.{ }^{16}\right]$.

\section{i) a. IIoT}

IIoT relies on smart machines for the efficient, routine and then human data collection and transmission. This report shows the tremendous potential for predictive maintenance, production initiatives, reliability of product energy quality and design optimisation. Consequently, IoS discusses value development through the materialization of the Product as Business model of a Service (PaaS). Now consumer product manufacturers are trying to create direct interaction with customers and improve their competitiveness through the provision of extra services and new sources of revenue $\left[{ }^{17}\right]$, and the technology support required IoS. IIoT uses intelligent devices to efficiently, consistently and then humanly collect and distribute data. This reports shows the great potential for predictive maintenance, production projects, product energy quality efficiency and optimization of design. Therefore, IoS explores the production of profit by materializing the product-as-a-services business model (PaaS). Consumer goods producers are trying now, by offering secondary services and creating alternate source,flows of income $\left[{ }^{17}\right]$, to build direct ties and to which enhance their leading position, and IoS offers the right technical infrastructure. In IoS technology, such as sensor-oriented devices, PaaS is enabling a business strategy that constantly feeds the provider's use of material and condition details and then can utilize the information of the users. purposes. $\left[{ }^{18}\right]$.

\section{ii) IoP}

IoP relies on a socio-technical framework, which is not end customers applications but active elements in the internet $\left[{ }^{19}\right]$. The IoP network integrates as a software the social devices (SDs) and the PaaS. The precursory features of digital devices (smartphones, for example) coordinate communications with many other Wireless-connected devices, while PaaS offers personal devices the ability to implement their programs, such as online social and background profiles.[$\left.{ }^{20},{ }^{21}\right]$.People put their lives online in human history, and show how they are of interest. Such data represent the social news and internet behaviors of people. Through gathering data and simulating them in the IoP system, businesses can predict new technologies that deliver results in real time. Cloud computing is a new innovation and is not having a common description. Its recent growth in hardware, virtualisation, delivery of internet services $\left[{ }^{22}\right]$. 


\section{iii) Cloud Computing}

Usage of cloud computing with software platform,Web- based interface and cloud communication enables con- nected resources to be incorporated $\left[{ }^{23}\right]$. It will in effect help to create the next generation of cloud development. $\left[{ }^{24}\right]$.

\section{iv) Big Data}

Its new generation technology helps organizations to derive value by identify, store and analyze large amounts of a data. It helps organizations better assess the vast amount of knowledge they possess, forecast what would be likely to occur next, or what steps need to be taken to achieve successful or effective results $\left[{ }^{25}\right]$. Which understands fast observations and decision- making patterns, and retains competitiveness $\left[{ }^{26}\right]$ ).

\section{v) Big Data Analytics}

Big data analytics, in particular, would allow manufacturers can enhance the utilization and efficiency of resources, increase product customization, optimize digital maintenance, avoid failures, streamline production and distribution chain management more successfully $\left[{ }^{27}\right]$.

\section{vii) Cognitive Manufacturing}

Cognitive service is used in IBM, example says that how big data analysis are generated [ $\left.{ }^{28}\right]$.

\section{vii) Blockchain}

Blockchain is also known as Distributed Technology (DT), It is the basis of crypto-currency like Ethereum and Bitcoin, however his features go well beyonds. It is irreversible, accessible and defines faith, as it makes open, decentralized, safe, reliable, fast, public and private technologies $\left[{ }^{28}\right]$. The development of blockchain is important in I-4.0 because cryptocurrency allow numerous digital devices to carry out transparent, stable, Simple and quick business transactions, completely automated in the IoT setting with no human assistance $\left[{ }^{29}\right]$. I- 4.0 develops systems for automation and blockchain which create trusted relationships among smart manufacturers, distributors and users. It brings machinery inside the smart factory into IIoT, CPS, and supply partners will allow. Augmented reality (AR) is an automation that enables the simulation of the graphics embedded in the real-time industries $\left[{ }^{30}\right]$. With growing advances in design and development, the $\left[{ }^{31}\right]$ fault is widely used to define, schedule, track, diagnose recover. Output outcomes are assisted by manufacturers preparation, maintenance activities, quality control and product design $\left[{ }^{32}\right]$.

\section{viii) Automobile Industry}

Growing on automation and robotics plays an sig- nificant part in the automotive industry. $\left[{ }^{33}\right]$.Market demands for robots increased as a result of industrial automation.Its benefits include minimal throughput, low fault frequency, excellent quality, minimized excess and then use $\left[{ }^{34}\right]$.

\section{ix). Cyber Security}

It is a major aspect of I- 4.0 providing organiza- tions with safe internet linking. The I- 4.0 will be challenged by its security and privacy concerns inside the environment $\left[{ }^{35}\right]$, "manufacturing things" link through the supply chain $\left.{ }^{36}\right]$ via 
the internet. I- 4.0 puts together consumer relationships and can deliver orders to a partner immediately in real-time industries. Manufacturing materials should help the concept of a 'smart factory' by enhancing production speed, design, reductions in value chain, developing software and industrial scale growth $\left[{ }^{37}\right]$. Simulation and its techniques for system operations design, check and execute $\left[{ }^{38}\right]$. Simulation and modeling in smart factories would be critical to normal life for real-time data, which include computers, products and humans $\left[{ }^{39}\right]$. This stops manufacturers from making errors. Fabrication studies show greater simulation capacity in future development technologies. CPS is really a collection of revolutionary technology which enable the unique combination and virtual capability operations $\left[{ }^{16}\right]$. It is managed and Tracked using software-based algorithms and closely connected to items from their users through theinternet.

\section{x) Semantic Technologies}

I-4.0 Semantic technologies attain IoT $\left[{ }^{40}\right]$, which links data and processes through IIoT. It offers tools that communicate by interfaces with each other, and prevents machinery from being combined by different manufacturers. In this case, the combination of semantic site with digital Web of Things (WoT) software will offer representation of information called Web Ontology Language $\left.{ }^{41}\right]$.

\section{I- 4.0 Principles}

\section{i) I-4.0-service Orientation}

Service orientation in I- 4.0 applies mainly to the business model (Maas) of a networked logistics system for the production of products. Inter-connectivity among companies as well as the interface between Connected devices and cloud services has developed a new method of development to communicate its needs automatically. In this setting several manufacturing processes from different industries can combine complex tasks $\left[{ }^{42}\right]$. Products were distributed as a service in the other model (PaaS), here consumers are subscribed to the product and the cost on an industry-based basis. IoS technology enables this business model, which can be incorporated into the monitoring products. Smart technology is a new generation of devices that integrates with various types of sensors that communicate with industry and during their process cycles capture, store and transmit data. $\left[{ }^{43}\right]$. This stage of smart products will interact with manufacturing industry-related details, How is the past state and how much measures are required to reach the destination $\left[{ }^{16}\right]$.

\section{ii) smart Factory - Automated Devices}

Smart factory is a connected system with smart machines and materials which automatically find the defect, timing and waste. Process efficiency is so needed in the current setting, industry automation and self-optimization are developed. It is dynamically integrated with the cps program, where resources are innovated as intelligent things $\left[{ }^{44}\right]$. It Will communicate with one another human resources via the $\left[{ }^{15}\right]$ IoP, WoTand IIoT. I- 4.0 Interoperability can be described atvarious levels including organizational, semantic, systemic and technological interoperability [7]. I- 4.0's other design theory is modularity, which switches from linear to planning, static structures, and inflexible manufacturing. This may respond to requirements that involve whole output levels and manufacturing outputs $\left.\left[{ }^{16,2}\right]\right)$.

\section{iii) Smart Technology - Intelligent Factory}

The emergence of new developments in robotics, such as CPS, IoT, cloud computing, robotics and user-based additive 
manufacturing products. This ex- plains why manufacturers not only meet consumers and address current requirements and expectations, but also IoP, visualization and Data analysis benefits to predict future business patterns and the needs of customers $\left[{ }^{7}, 15\right]$.

\section{iv) Decen Tralization}

Smart factory focused on decentralization such as Intelligent monitoring and auto-regulating mechanisms, which operates independently and makes its own decisions $\left[{ }^{16},{ }^{23}\right]$ ). Industries take advantage of decen- tralization for generalised planning and implementation of multiple processes. Virtualization allows "digital twin" of the sensor information collected in prototype form from the modern world based on Virtualisation or simulation[ 45,46$]$.

\section{v) Digital Twin}

A smart's digital twin allows the digital footprint of its past or current products across its production cycle, through product design. This provides a clearer understanding of the product's output at the point of purchase, but also helps businesses to analyze and develop the product $[45,35,42]$. I- 4.0 is typically Com- bined, actual-time and actual-world data in a range of measurements, including smart company, smart plant, products and business associates, real-time IoT apps $\left[{ }^{47,48}\right.$. Realtime functionality includes data gathering and data interpretation, decision-making and security threats based on current findings $[35,6]$.

\section{vi) System Integration}

System integration is the process of one device, offering a service for the company. It is focused on I-4.0 that smart items and other smart processes need to incorporate production systems and technologies. Its vertical and horizontal integration to link all information and functions across industry $\left[{ }^{20}\right]$.Responsibility in the business world includes such fields as labor and environmental regulations. The fourth industrial growth, robotics and automation of manufacturing would significantly impact work prospects in corporate industries. It is also regarded as a job creator. It focuses more on employment while believes that automation often creates more jobs than before, so I- 4.0 also creates new job opportunities, particularly in computer engineering, computer science and mathematics. I- 4.0'sgoal is to improve future skills in education $\left[{ }^{49}\right]$.The effects shift the division of work $\left.{ }^{16}\right]$ between humans and machines. From the I-4.0 organization reports, Human Resource Management (HRM) evaluates abil- ities for the workforce and recognizes the abilities of existing workers, and describes the expertise currently missing in the business $\left[{ }^{50,51,52}\right]$. But, the current workers don't live in a digitized warehouse, they are well-trained about the rules, conditions and workplace of the organization. The I-4.0 transition involves complete automation and procedures, the benefit of this change is to take one's own decision to be educated by experts and adapt them to the new technology and changes that are rising. Intelligent technology is characterized byintegration, automation, visibility, strategic thinking and flexibility, that targets traditional production into a completely automated and scalable process $\left[{ }^{12}\right]$. Moving towards future systems development begins with IIoT to create relations between the factory and horizontal or vertical integration of devices, databases, operations, and monitoring systems $\left[{ }^{23},{ }^{16}\right]$. The smart ERP, with data mining, makes digital twin, reflecting an entire system, past and present actions $\left[{ }^{45}\right]$. Figure 2. Describes the I-4.0 plan describes the fourth innovation, which affects the supply chain, which focuses primarily on the development of digitalized processes $\left[{ }^{15}\right]$.I-4.0Incorporatesdigitaltwinoperationswiththe development of a supply 
network [ ${ }^{45}$ ] based on the IT value chain. Its goal is first to improve the connectivity of the supply chain to achieve coordination between the value chain $\left[^{2}\right]$ The advantage of WoT and blockchain.

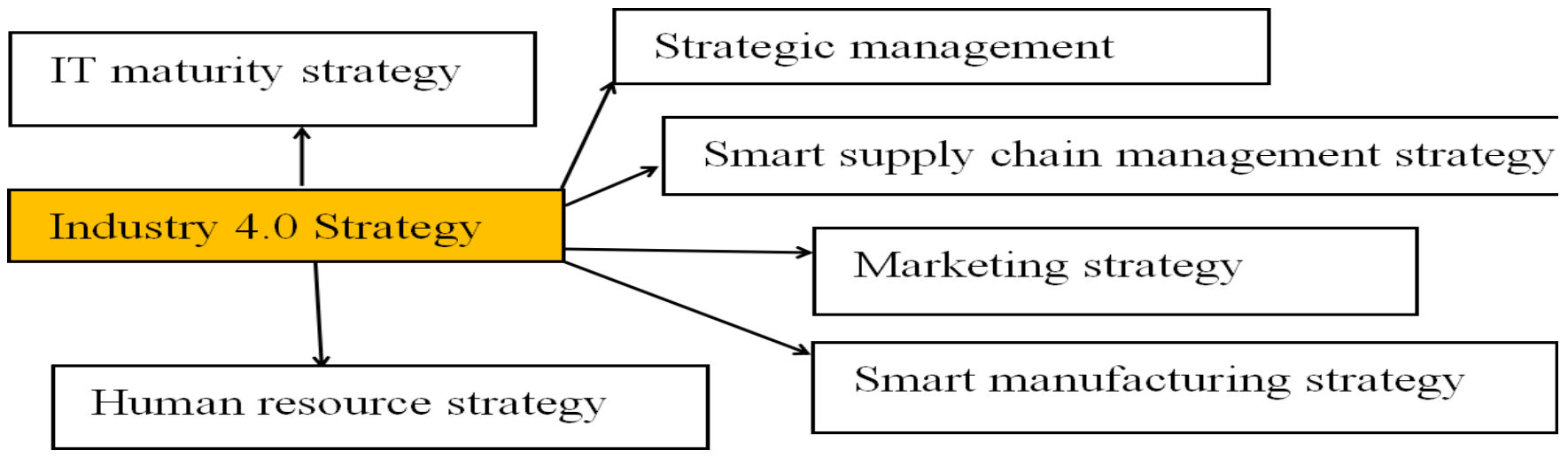

Figure2: I- 4.0 Strategy.

Eliminates information, data integrity and protection across various channels inside the [28] supply chain. A supply network participants should incorporate the information management, products, operations, financing, and manufacturing of expertise that supports the I- 4.0 transformation. The production of smart network and smart value chain, enables operations and processes to be Integrated along with Partners and Clients. This integration in effect offers internal and external supply chain systems $\left[{ }^{2}\right]$.

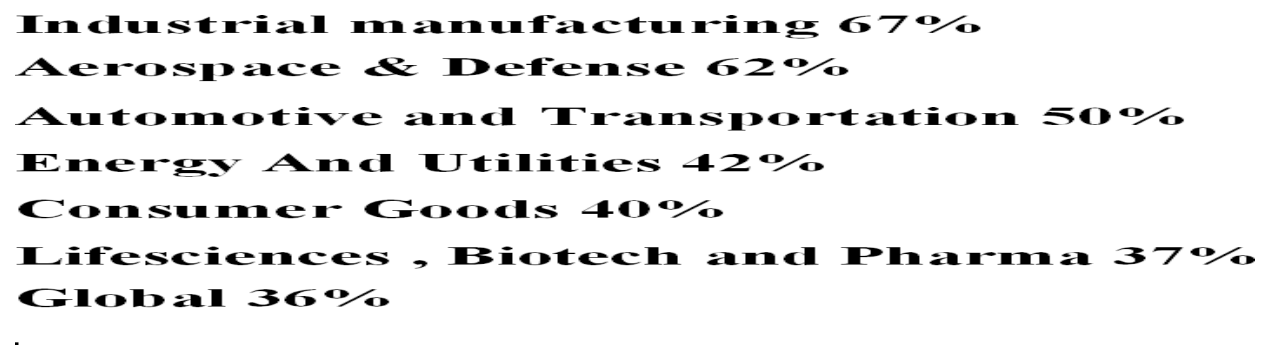

Figure 6: Smart Factory - Uses in Industries.

\section{SMART FACTORY MAJOR ROLE IN INDIANMANUFACTURING}

The digital innovation drives new IoT-connected technologies along with developments in AI and machine automation in an advanced manufacturing method called Smart Fabrication $[53,54]$. Industrial equipment that interacts automatically with users and other devices, with- out human interference. Innovation [ ${ }^{55}, 56$ ] emerges from real-time contact between industry and citizens. So, we're developing a new modern digital production process called modern factory. $\left[{ }^{57}\right]$.

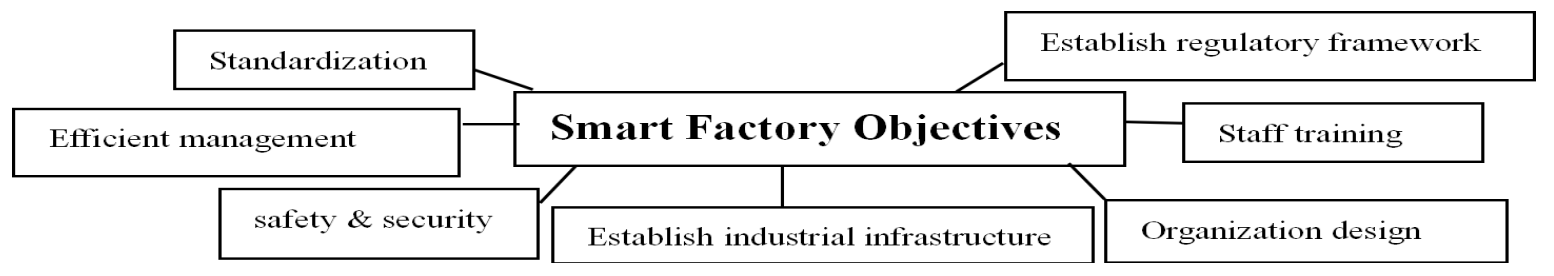

Figure 3: Smart Factory Objectives.

It is a connected, adaptive and scalable manufacturing device Which uses a continuous knowledge stream from Related activities and program development processes to change and adapt to new demands.figure.4. Explains the maturity 
model which improves smart factory production $\left[^{1}\right]$. Implementation of Smart Factories and Creativity in Processes. Intelligent manufacturing will drive a new industrial transition as per Data analysts[ $\left.{ }^{21}\right]$.In an interconnected system, Intelligent Factory is a network of devices, sensors and robots working with each other to manufacture cars and batteries more effectively, so that manufacturing processes turn their services via smart factory automation. Indian production drives transition in the manufacture of all goods that are of great assistance to our everyday lives [ ${ }^{58}$ ]. Explains, the percentage of smart factory use in Indian industry.

\begin{tabular}{|l|l|l|}
\hline LEVELs & MATURITY MODEL & EXPLANATION \\
\hline Level 1 & comnected technologies & add complexity to implementing smart factories. \\
\hline Level 2 & structured data gathering and data sharing & create models for structured data gathering and sharing. \\
\hline Level 3 & real- time process analytics \& optimization & focus benefits from the data and the system. \\
\hline Level $\mathbf{4}$ & smart, predictable manufacturing & implementation of smart factories. \\
\hline
\end{tabular}

Figure 4: Smart Factory Maturity Model.

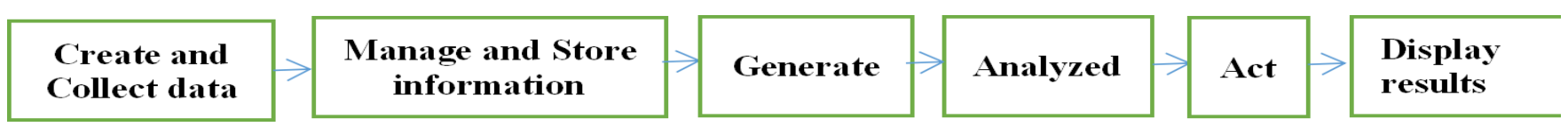

Figure 5: Smart Factory Notions.

\section{INDIAN SMART FACTORY - CASE STUDIES}

For that demands, the companies put automated machinery in favor of humans to produce a product. Figure.5. Explains the notion of smart factory cycle in industry. Many of India's big digital transformation-driven industries, Figure.7. Explains the smart factory focused industry case study they follow:

The figure.7. S.No with following citations of the case study. $1\left[{ }^{59}, 39\right], 2[60,61,62,63], 3\left[{ }^{64}, 65\right], 4\left[{ }^{66}\right], 5\left[{ }^{59}\right]$, $6\left[{ }^{67}, 68\right], 7\left[{ }^{69}\right], 8\left[{ }^{70}\right], 9\left[{ }^{71},{ }^{72},\right], 10\left[{ }^{73}, 74\right], 11\left[^{75}\right], 12\left[{ }^{76}, 77\right], 13\left[{ }^{78}\right], 14\left[{ }^{79}\right], 15\left[{ }^{80}, 81\right]$

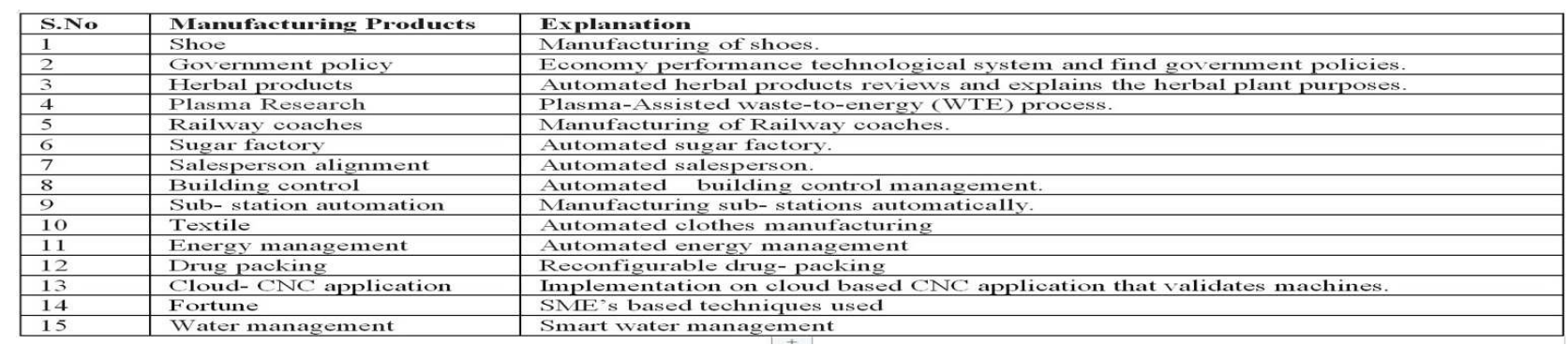

Figure 7: Smart Factory - Case Study in India

\section{CONCLUSIONS}

Artificial Intelligence (AI) is a catalyst in Digital Transformation for Indian Manufacturing making it more intelligence smart factory.

\section{REFERENCES}

1. B. Chen, J. Wan, L. Shu, P. Li, M. Mukherjee, and B. Yin,IEEE Access PP, 1 (2017).

2. M. Ghobakhloo,Journal of Manufacturing TechnologyManagement (2018), 10.1108/JMTM-02-2018-0057.

3. R. David, J. Stahre, T.Wuest, O. S. Noran, P. Bernus, A. F. Berglund, and D. Gorecky(2016). 
4. M. Mabkhot, A. Al-Ahmari, B. Salah, and H. Alkhalefah,Machines 6, 23 (2018).

5. N. Vaskenly and M. Dhanya, International Journal of Pure and Applied Mathematics 118, 505 (2018).

6. A. Moeuf, R. Pellerin, S. Lamouri, S. Tamayo Giraldo, andR. Barbaray, International Journal of Production Research, 1 (2017).

7. Y.Lu,Journal of IndustrialInformation Integration 6(2017), 10.1016/j.jii.2017.04.005.

8. M. Brettel, N. Friederichsen, M. A. Keller, and M. Rosen- berg(2014).

9. H.-L. Yang, T.-W. Chang, and Y. Choi,Sustainability10,2779(2018).

10. P. Rawat and J. Purohit (2019).

11. A. Mathur, G. Dangayach, M. Mittal, and M. Sharma,Measuring Business Excellence 15, 77 (2011).

12. A. Khan and $K$. Turowski, "A survey of current challengesin manufacturing industry and preparation for industry 4.0," (2016) pp. 15-26.

13. A. Al-Fuqaha, m. guizani, M. Mohammadi, M. Aledhari, and M. Ayyash,IEEE Communications Surveys amp Tutorials17, Fourthquarter 2015 (2015).

14. L. Atzori, A. Iera, and G. Morabito, Computer Networks, 2787 (2010).

15. S. Wang, J. Wan, D. Li, and C. Zhang,International Jour-nal of Distributed Sensor Networks 2016, 1 (2016).

16. A. Gilchrist, "Introducing industry 4.0," (2016) pp. 195-215.

17. E. Becker, T. Goetz, V. Morger, and J. Ranellucci,Teach-ing and Teacher Education 43, 15-26 (2014).

18. S. Leminen, W. Mika, and A.-G. Nyström,TechnologyInnovation Management Review 2, 6 (2012).

19. C. Conti, R. Lanzara, M. Scipioni, M. Iasenza, M. Guag-nano, and M. Fulcheri,Frontiersin Psychology 8(2017),

20. 10.3389/fpsyg.2017.02125.

21. D. SaezM,Journal of Clinical Movement Disorders 2, 2(2015).

22. G. Lampropoulos, K. Siakas, and T. Anastasiadis,Inter-nationalJournalofEntrepreneurialKnowledge7,4(2019).

23. T. Oliveira, M. Thomas, and M. Espadanal,InformationManagement 51 (2014), 10.1016/j.im.2014.03.006.

24. L. Xu, W. He, and S. Li,IEEE Transactions on IndustrialInformatics 10, 2233 (2014).

25. B. K. Ooi, K.-G. Chan, B. H. Goh, and W. H. Yap,Fron-tiersinPharmacology9(2018), 10.3389/fphar.2018.01308.

26. S. Lavalle, E. Lesser, R. Shockley, M. Hopkins, and N. Kr-uschwitz, MIT Sloan Management Review 52, 21 (2011).

27. J. Difranza,Addiction109 (2014), 10.1111/add.12670.

28. T.Nguyen, L.Zhou, V. Spiegler, P.Ieromonachou, and Y. Lin,Computers Operations Research (2017),10.1016/j.cor.2017.07.004.

29. S. Underwood,Communications of the ACM 59, 15 (2016).

30. G. Dorleon and S. Gervais, (2017).

31. C. S. Kuan, S. Yew, C. Chan, Y. Toh, K. Lee, W.-H. Cheong, W.-Y. Yee (Sunny), C. Hoh, S.-J. Yap, and K. P. Ng, Database The Journal of Biological Databases and Cu-ration 2016, 1 (2016). 
32. A. Doshi, K. Asawa, N. Bhat, M. Tak, P. Dutta, T. Bansal, and R. Gupta, Clujul Medical 90 (2017), 10.15386/cjmed-768.

33. V. Elia, M. Gnoni, and F. Tornese, Measuring circular economy strategies through index methods 142 (2016),10.1016/j.jclepro.2016.10.196.

34. J. Torresen,Frontiersin Robotics and AI $\mathbf{4}$ (2018),10.3389/frobt.2017.00075.

35. B. Esmaeilian, S. Behdad, and B. Wang, Journal of Manufacturing Systems 39, 79 (2016).

36. L. Thames and D. Schaefer, "Industry 4.0: An overview ofkey benefits, technologies, and challenges," (2017).

37. J. Mehnen, H. He, S. Tedeschi, and N. Tapoglou, "Practi-cal security aspects of the internet of things," (2017) pp. $225-242$.

38. H.Lasi, P. Fettke, H.-G. Kemper, T. Feld, and M. Hoffmann,Business Information Systems Engineering 6, 239(2014).

39. J. Kocian, J. Koziorek, and M. Pokorný (2011) pp. 322- 327.

40. G. Erboz (2017).

41. V. Janev and S. Vraně̌, Information Processing and Man-agement47, 507-517 (2011).

42. A. Thuluva, D. Anicic, and S. Rudolph (2018).

43. F. Tao and Q. Qi,IEEE Transactions on Systems, Man, and Cybernetics: Systems 49, 81(2019).

44. C. Baumgarth, F. Lückenbach, H. Schmidt,andJ. Henseler (2016).

45. M. Roeglinger, L. Püschel, and H. Schlott (2016).

46. B. Schleich, N. Anwer, L. Mathieu, and S. Wartzack, CIRP Annals - Manufacturing Technology 66, 141 (2017).

47. F. Madrigal Moreno, J. Gil Lafuente, F. Avila, and S. Madrigal Moreno,International Journal of Marketing Studies 9 (2017), 10.5539/ijms.v9n5p135.

48. J. Lee, B. Bagheri, and H.-A. Kao,SME Manufacturing Letters 3 (2014), 10.1016/j.mfglet.2014.12.001.

49. P. Cicconi, A. Russo, M. Germani, M. Prist, E. Pallotta, and A. Monteriù (2017) pp. 1-6.

50. T.-H. Choi,Journal of Education Policy (2017),10.1080/02680939.2017.1290280.

51. F. Hecklau, M. Galeitzke, S. Flachs, and H. Kohl, ProcediaCIRP 54, 1 (2016).

52. F. Hecklau, R. Orth, F. Kidschun, and H. Kohl, (2017).

53. M. Piccarozzi, B. Aquilani, and C.Gatti,Sustainability10, 3821 (2018).

54. E. Oztemel and S. Gursev,Journal of Intelligent Manufac-turing (2018), 10.1007/s10845-018-1433-8.

55. M. Blackburn, J. Alexander, J. Legan, and D. Klabjan,Research-Technology Management 60, 43 (2017).

56. M. Iansiti and K. Lakhani, Harvard business review 92(2014).

57. M. Lambrou and M. Ota (2017).

58. K. Zhou, T. Liu, and L. Zhou (2015) pp. 2147-2152.

59. G. Li, Y. Hou, and A. Wu, Chinese Geographical Science27, 626 (2017). 
60. R. Narain, R. Yadav, and J. Antony, International Journal of Productivity and Performance Management 53, 109(2004).

61. D. Leahy and J. Neary, International Journal of Industrial Organization 25, 1089 (2007).

62. M. Bleda and P. Río, Research Policy (2013),10.1016/j.respol.2013.02.008.

63. S. Miglani, "The growth of the indian automobile industry: Analysis of the roles of government policy and other enabling factors,” (2019) pp. 439-463.

64. P. John,PhysicaScripta2002, 86 (2006).

65. N. Dubey, R. Kumar, and P. Tripathi, Curr Sci 86 (2003).

66. K. Ramawat and S. Goyal, “The indian herbal drugs sce-narioinglobalperspectives,”(2008)pp.325-347.

67. N. Themelis and A. Vardelle, "Plasma-assisted waste-to-energy (wte) process plasma-assisted waste-to-energy pro- cess waste-to-energy (wte) process es," (2012) pp. 8097-8112.

68. M. Schönheit and T. Kuhnert, WT Werkstattstechnik107, 219 (2017).

69. L. Rózsa, International Sugar Journal 105 (2003).

70. R. Cascio, B. John Mariadoss, and N. Mouri,IndustrialMarketing Management 39, 1088 (2010).

71. T. Sauter, S. Soucek, W. Kastner, and D. Dietrich,IEEEIndustrial Electronics Magazine - IEEE IND ELECTRONMAG 5, 35 (2011).

72. R. Jr, J. Bowen, H. Combs, D. Dunn, M. Hildreth, andA. Pilcher,Industry Applications Magazine, IEEE 11, 12 (2005).

73. H. Li and L. Wang,Energy Procedia 12, 113-119 (2011).

74. R. Riedel, N. Göhlert, and E. Müller, WT Werkstattstech-nik105, 195 (2015).

75. E. Gökalp, M. Gökalp, and P. Eren, “Industry 4.0 revolution in clothing and apparel factories: Apparel 4.0," (2018) pp. 169-183.

76. M. Medojevic, P. Díaz, I. Cosic, A. Rikalovic, N. Sremčev, and M. Lazarevic, "Energy management in industry 4.0 ecosystem: a review on possibilities and concerns," (2018) pp. 0674-0680.

77. B. Ding,Process Safety and Environmental Protection 119(2018), 10.1016/j.psep.2018.06.031.

78. J. Wan, S. Tang, D. Li, M. Imran, C. Zhang, C. Liu, andZ. Pang,IEEETransactions on Industrial Informatics PP, 1(2018).

79. V. Narwane, B. Narkhede, R. Raut, I. Siddavatam, andB. Dr. Ravishankar,IndustrialEngineering Journal 11(2018), 10.26488/IEJ.11.7.1132.

80. J. Müller,O. Buliga,and K.-I. Voigt,Tech-nologicalForecasting and Social Change (2018),10.1016/j.techfore.2017.12.019.

81. K. Shahanas and P. Sivakumar, Procedia Computer Sci-ence92, 142 (2016).

82. T. Robles, R. Alcarria, D. Martín, M. Navarro, R. Calero,S. Iglesias, and M. López, Journal of Wireless MobileNet-works, Ubiquitous Computing, and Dependable Applica-tions6, 4(2015). 